\title{
Evaluation of Reproductive Concerns and Biographical Impact of Breast Cancer in Young Patients
}

\author{
Maximiliane Burgmann ${ }^{a}$ Kerstin Hermelink $^{a} \quad$ Alex Farr $^{b} \quad$ Friederike van Meegen $^{a}$ \\ Annika Heiduschk ${ }^{\mathrm{a}}$ Jutta Engel ${ }^{\mathrm{a}}$ Thomas Kolben $^{\mathrm{C}}$ Tom Degenhardt ${ }^{\mathrm{a}}$ Nina Ditsch $^{\mathrm{a}}$ \\ Sven Mahner ${ }^{\mathrm{a}}$ Nadia Harbeck $^{\mathrm{a}}$ Rachel Würstlein ${ }^{\mathrm{a}}$ \\ a Breast Center, Department of Gynecology and Obstetrics and Comprehensive Cancer Center of LMU, University of Munich (LMU), \\ Munich, Germany; \\ ${ }^{b}$ Breast Center (Comprehensive Cancer Center), Department of Gynecology and Obstetrics, Medical University of Vienna, Vienna, Austria; \\ ${ }^{c}$ Munich Cancer Registry (MCR) of the Munich Tumor Center at the Institute for Medical Information Processing, \\ Biometry and Epidemiology (IBE), University Hospital of Munich (LMU), Munich, Germany
}

\section{Keywords}

Breast cancer - Premenopausal patients · Fertility preservation - Parenthood concerns - Return to work

\section{Summary}

Background: This study evaluates interventions offered to young breast cancer (BC) patients, including fertility preservation, genetic testing, and counseling for parenthood concerns, and analyzes the effect of BC on biographical issues. Methods: Women who were diagnosed with $\mathrm{BC}$ at the age of 18-40 years and who underwent treatment at the Breast Center, Ludwig-Maximilian University (LMU) in Munich between 2006 and 2013, were eligible for this study. Patients received a self-developed questionnaire which covered the following topics: fertility preservation, family planning, genetic testing, parenthood concerns and children's needs, partnership status, and employment situation. Results: Re-evaluating their initial decision on fertility preservation, $76.4 \%$ of patients reported satisfaction with their decision. After BC diagnosis, $45.8 \%$ reported to have maternal desire, but only $21.7 \%$ actually planned to have children. $41.7 \%$ of patients missed sufficient counseling regarding parenthood concerns. Analysis of individual employment situations showed that the time period until the return to work was longer in patients who received chemotherapy. The majority of patients $(71.6 \%)$ did not report changes in their partnership status. Conclusion: Young BC survivors report a lack of communication related to parenthood concerns and future conception, but are satisfied with counseling regarding fertility preservation and genetics.

(C) 2018 S. Karger GmbH, Freiburg

\section{Introduction}

Breast cancer (BC) in young women is a complex disease which strikes in a phase of life when young women are at the peak of their reproductive years and when family planning, professional career, and partnership are very important. By definition of the International Consensus Conference for Breast Cancer in Young Women (BCY1) in 2012 as well as EUSOMA (European Society of Breast Cancer Specialists) in 2013, a 'young patient' is defined as aged $<40$ years at the time of $\mathrm{BC}$ diagnosis [1-3], and there is still an increase in the incidence of $\mathrm{BC}$ among young Caucasian women $[4,5]$. It is known that premenopausal women are at risk for more aggressive tumor grade and larger tumor size at diagnosis and therefore poorer prognosis than older women [6-8]. Thus, they are likely to undergo more intensive treatment [7]. Young women also have a need for a more comprehensive approach to improve quality of life after cancer, including fertility preservation [9], childcare, and genetic factors.

Chemotherapy [10] is widely used in young BC patients, potentially leading to premature ovarian failure and temporary or permanent infertility. Although fertility preservation has been well established in medical counseling of young women, there is still uncertainty as to whether a young patient will be able to conceive after $\mathrm{BC}$ treatment when she is advised to delay pregnancy for 2 years after being diagnosed [11]. Additionally, following the results of the ATLAS trial, women with endocrine-sensitive tumors may receive extended adjuvant endocrine therapy for more than 5 years, which may also impair fertility [12]. Conversely, initiation and continuation of endocrine therapy are also negatively impacted by fertility concerns [13]. For the group of young BC patients who have young children (an estimated $18.6 \%$ in the USA [14]), there may be an additional need for professional and psychosocial support.

\section{KARGER}

() 2018 S. Karger GmbH, Freiburg

Fax +497614520714
Dr. med. Maximiliane Burgmann, MD Breast Center, Department of Gynecology and Obstetrics and Comprehensive Cancer Center of LMU University of Munich (LMU)

Marchioninistraße 15, 81377 München, Germany maximiliane.burgmann@med.uni-muenchen.de 
Table 1. Patient and treatment characteristics $(n=88)$ according to patients' statements

\begin{tabular}{|c|c|c|c|c|c|c|}
\hline & Mean & Minimum & Maximum & & & \\
\hline Age at time of assessment, years & $38.4(\mathrm{SD} 5.3)$ & 23 & 46 & & & \\
\hline Age at diagnosis, years & $34.5(\mathrm{SD} 4.5)$ & 21 & 39 & & & \\
\hline \multirow[t]{2}{*}{ Time since diagnosis, years } & $4.4(\mathrm{SD} 2.3)$ & 1 & 8 & & & \\
\hline & Married & Partnership & Single & Divorced & & \\
\hline \multirow{2}{*}{$\begin{array}{r}\text { Partnership status at time of } \\
\text { diagnosis }(\mathrm{n}=87), \mathrm{n}(\%)\end{array}$} & $44(50 \%)$ & $26(29.5 \%)$ & $13(14.8 \%)$ & $4(4.5 \%)$ & & \\
\hline & No change & $\begin{array}{l}\text { Breakup/ } \\
\text { divorce }\end{array}$ & Marriage & New partnership & $\begin{array}{l}\text { Marriage to a new } \\
\text { partner }\end{array}$ & \\
\hline \multirow{2}{*}{$\begin{array}{l}\text { Changes in partnership status } \\
\text { since diagnosis }(\mathrm{n}=88), \mathrm{n}(\%)\end{array}$} & $63(71.6 \%)$ & $9(10.2 \%)$ & $9(10.2 \%)$ & $6(6.8 \%)$ & $1(1.1 \%)$ & \\
\hline & No graduation & Lower school & Middle school & Higher school & University degree & Other \\
\hline \multirow{2}{*}{$\begin{array}{l}\text { Highest level of education } \\
\qquad(\mathrm{n}=86), \mathrm{n}(\%)\end{array}$} & $1(1.1 \%)$ & $6(6.8 \%)$ & $25(28.4 \%)$ & $18(20.5 \%)$ & $35(39.8 \%)$ & $1(1.1 \%)$ \\
\hline & German & Other & & & & \\
\hline \multirow[t]{2}{*}{ Nationality $(\mathrm{n}=87), \mathrm{n}(\%)$} & $67(76.2 \%)$ & $20(22.7 \%)$ & & & & \\
\hline & Not employed & Part time & Full time & & & \\
\hline $\begin{array}{l}\text { Employment status before } \\
\text { diagnosis }(\mathrm{n}=88), \mathrm{n}(\%)\end{array}$ & $15(17 \%)$ & $26(29.5 \%)$ & $47(53.5 \%)$ & & & \\
\hline \multirow{2}{*}{$\begin{array}{l}\text { Employment status at time of } \\
\text { assessment }(\mathrm{n}=88), \mathrm{n}(\%)\end{array}$} & $18(20.5 \%)$ & $31(35.2 \%)$ & $39(44.3 \%)$ & & & \\
\hline & $\begin{array}{l}\text { Hospital social } \\
\text { services }\end{array}$ & Psychooncology & Pastoral care & $\begin{array}{l}\text { Breast care } \\
\text { nurse }\end{array}$ & Support group & \\
\hline \multirow{2}{*}{$\begin{array}{l}\text { Contact with supportive care } \\
\text { programs }{ }^{\mathrm{a}}, \mathrm{n}(\%)\end{array}$} & $32(36.4 \%)$ & $37(42 \%)$ & $14(15.9 \%)$ & $11(12.5 \%)$ & $5(5.7 \%)$ & \\
\hline & $\begin{array}{l}\text { Breast-conserving } \\
\text { surgery }\end{array}$ & $\begin{array}{l}\text { Mastectomy - } \\
\text { no reconstruction }\end{array}$ & $\begin{array}{l}\text { Mastectomy - } \\
\text { implant-based } \\
\text { reconstruction }\end{array}$ & $\begin{array}{l}\text { Mastectomy - } \\
\text { autologous } \\
\text { reconstruction }\end{array}$ & $\begin{array}{l}\text { Sentinel lymph } \\
\text { node biopsy }\end{array}$ & $\begin{array}{l}\text { Axillary } \\
\text { dissection }\end{array}$ \\
\hline \multirow[t]{2}{*}{ Surgical therapy ${ }^{\mathrm{a}}, \mathrm{n}(\%)$} & $52(59.1 \%)$ & $7(8 \%)$ & $18(20.5 \%)$ & $11(12.5 \%)$ & $48(54.5 \%)$ & $26(29.5 \%)$ \\
\hline & $\begin{array}{l}\text { Regional radio- } \\
\text { therapy }\end{array}$ & $\begin{array}{l}\text { Neoadjuvant } \\
\text { CTX }\end{array}$ & Adjuvant CTX & $\begin{array}{l}\text { Neoadjuvant }+ \\
\text { adjuvant CTX }\end{array}$ & Trastuzumab & $\begin{array}{l}\text { Endocrine } \\
\text { therapy }\end{array}$ \\
\hline Adjuvant therapy ${ }^{\mathrm{a}}, \mathrm{n}(\%)$ & $66(75 \%)$ & $26(29.5 \%)$ & $39(44.5 \%)$ & $10(11.4 \%)$ & $25(28.4 \%)$ & $67(76.1 \%)$ \\
\hline
\end{tabular}

${ }^{a}$ Multiple answers were possible.

$\mathrm{SD}=$ Standard deviation; CTX = chemotherapy.

The majority of BC patients - not just in the young subgroup are members of the workforce $[15,16]$. BC survival rates have increased over the past decades, and a return to work, which is associated with normal life, social recovery, and thus better quality of life, needs to be achieved [17].

So far, little is known about the impact of the disease on partnership. In studies analyzing the association between early-stage BC and marital status, no significant increase in the risk of divorce compared to women without cancer could be demonstrated [18, 19].

In view of the rising number of young women diagnosed with $\mathrm{BC}[4,5]$, the present study aimed to evaluate interventions particularly offered to young BC patients, including fertility preserva- tion, genetic testing, and counseling for parenting concerns, and to analyze the effect of the disease on biographical issues such as family planning, professional career, and partnership status.

\section{Patients and Methods}

\section{Patient Characteristics}

In this cross-sectional, monocentric study, we enrolled patients aged between $\geq 18$ and $\leq 40$ years at the time of diagnosis. Eligible patients were retrospectively identified by the Munich Cancer Registry of the Munich Tumor Center at the Ludwig-Maximilian University of Munich (LMU). Inclusion criteria were treatment at the LMU Breast Center between 2006 and 2013, date of 
diagnosis more than 6 months prior to the assessment, residency in Germany, and the ability to speak and understand the German language. The study protocol was approved by the LMU ethics review committee. Written informed consent was obtained from all participants in the study.

\section{Assessments}

In 2014, patients received a self-developed questionnaire by mail addressing the topics of fertility preservation and family planning, genetic testing, parenting issues and children's needs, partnership status, and employment situation, focusing on the time before and after the $\mathrm{BC}$ diagnosis.

Every issue addressed by the questionnaire consisted of several sub-items in a multiple choice manner. Referring to special interventions for young patients, it was asked whether fertility preservation and genetic testing had been offered and implemented and whether the patient was currently satisfied with her own decisions. Patients with children were asked to evaluate the medical counseling regarding their children's needs. Detailed data were collected on partnership and housing situation, employment status, return to work, as well as on preand post-treatment income. In addition, questions about the previous and current desire to bear children as well as medical data were part of the questionnaire.

\section{Statistical Analyses}

Continuous data are given as median (range) or mean \pm standard deviation (SD), unless otherwise stated. Discrete data are presented as numbers (n) and percentages (\%). A 2 -sided p value of $<0.05$ was considered statistically significant. Mann-Whitney-U test and multivariable linear regression were used to determine predictors of time to return to work. Proportions of part- and fulltime employment at diagnosis and at the time of the assessment were compared using McNemar's test. All statistical analyses were carried out using SPSS statistics 22 (IBM Corp., Armonk, NY, USA).

\section{Results}

\section{Patient Characteristics}

Of an initial 219 patients, 59 had to be excluded (e.g., living abroad, unknown address, deceased). Of the 160 patients eligible to participate in the study, 88 sent back their questionnaire, corresponding to a $55 \%$ response rate. Our cohort had a mean age of 34.5 years at the time of diagnosis (SD 4.5; range 21-39 years), and the mean time from primary diagnosis was 4.3 years (SD 2.3; range $1-8$ years). At the time of assessment, the mean age was 38.4 years (SD 5.3; range 23-46 years). 9 (10.2\%) patients had developed distant metastases since the initial diagnosis, $5(5.7 \%)$ patients already had M1 disease at the time of the primary diagnosis (table 1).

\section{Reproductive Concerns}

According to the patients' answers, fertility issues had been discussed with $58(65.9 \%)$ patients. $35(40.7 \%)$ patients who stated a desire to have children had been offered fertility preservation. 21 (23.9\%) patients received fertility preservation measures. Of these, $1(4.5 \%)$ patient regretted her decision, 17 (81\%) patients would make the same decision again, and $3(14.3 \%)$ patients were not sure. Of the 55 patients who retrospectively evaluated their decision on fertility preservation, $42(76.4 \%)$ were still satisfied with their decision, 3 (5.5\%) expressed regret, and 10 (18.2\%) were not sure. $6(6.8 \%)$ patients had given birth to $1(\mathrm{n}=4)$ or 2 children (n $=2$ ) after treatment. Out of this group, 3 patients had been pregnant at the time of diagnosis.
A total of $38(45.8 \%)$ patients stated a current desire to have (more) children, while 32 (39.4\%) did not, and 13 (14.8\%) were not sure $(\mathrm{n}=83) .18(21.7 \%)$ patients planned to have (more) children, $52(62.7 \%)$ did not, and $13(15.7 \%)$ were not sure $(\mathrm{n}=83) .15$ (29.4\%) patients reported a potential negative impact of pregnancy on $\mathrm{BC}$ prognosis to be the main reason why they did not want to become pregnant. 14 (27.5\%) patients feared a shortened life expectancy, $10(19.6 \%)$ patients were afraid of infertility after treatment, 13 (25.5\%) of other cancer-related issues, and 8 (15.7\%) of issues unrelated to cancer (multiple answers were possible).

\section{Genetic Testing}

A total of $57(64.8 \%)$ patients reported that they had been offered testing for breast and ovarian cancer susceptibility genes. Of these patients, 43 (75.4\%) had undergone genetic testing, $6(6.5 \%)$ had declined, and 8 (14\%) had not yet decided. None of the patients regretted their decision, 1 (2\%) patient who had consented to be tested felt not sure about her decision, and all other patients (98\%) would make the same decision again.

\section{Parenting Concerns}

Of $40(45.5 \%)$ women who had children at the time of diagnosis, only $13(32.5 \%)$ stated that their children's needs had been discussed with the medical staff. Women reported that counseling regarding parenting concerns had been sufficient $(\mathrm{n}=11,30.6 \%)$, insufficient $(n=15,41.7 \%)$, or not necessary $(n=10,27.8 \%)(n=36)$.

\section{Professional Career}

At diagnosis, 73 (83\%) patients were employed and $15(17 \%)$ were not $(\mathrm{n}=88)$ (table 1$)$. At the time of assessment, $63(86.3 \%)$ of those patients who had been employed at the time of diagnosis had returned to work. Of the $9(13.7 \%)$ patients who had not returned to work, 3 had distant metastases. The mean time to return to work was 10 months (SD 5.7, $\mathrm{n}=59$ ) and differed significantly between the 48 patients who received chemotherapy [10] and the $11 \mathrm{pa}$ tients who did not $(11.4 \pm 5.3$ months vs. $3.6 \pm 2.4$ months; $p$ $<0.001)$. In a regression analysis, chemotherapy significantly predicted the time to return to work $(\mathrm{p}=0.01)$. No other treatments (e.g., endocrine therapy, radiotherapy, axillary dissection) or demographic factors (age at diagnosis, education, partnered/single at diagnosis, children/no children at diagnosis) had a significant impact on the time to return to work (data not shown). In the subgroup analysis of patients without distant metastases, the proportions of patients who were employed at the time of diagnosis and assessment, respectively, were identical ( $\mathrm{n}=73,82.9 \%$ vs. $\mathrm{n}=70$, $79.5 \%)$. More patients were working part-time at the time of the assessment $(\mathrm{n}=29,36.7 \%)$ than at diagnosis $(\mathrm{n}=22,28 \%)$, while $42(53 \%)$ and 35 (44\%) patients were working full-time at the time of diagnosis and assessment, respectively $(n=79)$ (table 1$)$. The difference in the proportion of part-time and full-time employment at the time of diagnosis or assessment was not significant $(\mathrm{p}=0.07)$.

A change of job between pre- and post-treatment was reported by $19(21.6 \%)$ patients. With regard to income, 4 (23.5\%) patients 
reported no difference in pre- and post-treatment income, while 8 (42.1\%) reported lower income and 5 (29.4\%) reported higher income $(\mathrm{n}=17)$. Career opportunities offered by the current job were judged to be equal ( $\mathrm{n}=4,28.6 \%)$, worse ( $\mathrm{n}=4,28.6 \%)$, or better $(n=6,42.9 \%)(n=14)$.

\section{Partnership Status}

Regarding partnership status, 63 (71.6\%) patients did not report any changes. Equal proportions of women had divorced/separated from or married the partner they had been in a relationship with at the time of the initial diagnosis ( 9 patients, $10.2 \%$, each), while 6 $(7.9 \%)$ patients had entered into a new relationship or marriage $(\mathrm{n}=88)$.

\section{Discussion}

This cross-sectional study evaluates interventions particularly offered to young BC patients, including fertility preservation, genetic testing, and counseling for parenting concerns, and analyzes the effect of the BC diagnosis on biographical issues, such as family planning, professional career, and partnership status. So far, this topic has been considerably underrepresented in the current literature.

\section{Reproductive Concerns}

Our findings indicate that addressing fertility issues and parenthood concerns during medical counseling are of highest importance. Women seek objective information about existing data, which is particularly important since many decisions seemed based on misinformation. The majority of patients with a current desire to have children decided against a pregnancy because they were afraid of cancer-related effects, such as shortened life expectancy or a negative impact of a pregnancy on $\mathrm{BC}$ prognosis. In the study by Ruddy et al. [20] analyzing 600 women with BC, $9 \%$ of those with maternal desire did not plan a pregnancy because they were afraid of cancer recurrence, while the BIG 3-98 study reported that $40 \%$ of women did not fulfill their desire to have children due to this anxiety [21]. In our cohort, only $21.7 \%$ of those patients with a desire for motherhood decided to have more children after BC diagnosis. Increased knowledge and skills for selfmanagement are needed, since post-treatment problems were reported to be associated with depression, anxiety, and stress in BC survivors [22-25].

Our assessment showed that patients frequently missed parenthood issues being brought up during medical counselling and stated that their children's needs had not been adequately addressed during the consultations. Mothers need to be supported and instructed on how to talk to their children at a time where they themselves struggle to get enough information, make decisions, and integrate the disease into their daily lives [26-28]. This communication needs to maintain hope while also being honest with the children [28]. In our cohort, women reported a high level of satisfaction regarding their previous decision on genetic testing and fertility preservation, which suggests adequate counseling and information on these issues. Therefore, intense cooperation of fertility preservation specialists, oncologists, and other health care workers with the patient is very important [29]. Since our institution collaborates with fertility networks such as FertiProtekt ( $w w w$. fertiprotekt.de), patients at our breast center were likely to be well informed about the different possibilities of fertility preservation [30]. As fertility is an issue of major interest for the majority of young $\mathrm{BC}$ survivors, knowledge about fertility preservation as well as the prospect of conceiving after $\mathrm{BC}$ treatment promote motivation to survive and positively influence $B C$ patients [31-33].

Finally, the BC diagnosis influences patients' decisions regarding reproductive concerns so that information on new strategies as well as improved communication are needed to better support young BC patients. Clinicians must educate their young patients about the available, albeit limited, data regarding the impact of a future pregnancy on $\mathrm{BC}$ prognosis in order to support their patients to manage their own decisions.

\section{Biographical Issues}

Our analysis confirmed data of previous studies reporting that a $\mathrm{BC}$ diagnosis influences neither partnership nor employment status $[34,35]$. In general, data on the association between cancer and marital stability are scarce. In light of increasing divorce rates in Europe and North America, this issue was of particular interest in our analysis [36]. Here, we decided to exclude the few women with metastatic disease in order to have a homogeneous collective. Studies among women with early-stage $\mathrm{BC}$ did not show an increased risk for divorce in patients compared to women without $\mathrm{BC}$, independent of the oncological treatment [18, 19, 35, 37].

Regarding professional life, our data indicate that chemotherapy was a reason for a delayed return to work. As other authors reported, the return to work in cancer patients is not only a measure of recovery and a positive step towards the future, it is also associated with social and financial support and may therefore be an important component of better quality of life [17, 38-40]. Young patients under the age of 40 are in an active phase when professional life and career may play an important role. Thus, young women should be supported and motivated to maintain their employment and return to work, particularly after completion of chemotherapy.

When interpreting our results, the limitations of our study need to be considered. This study was implemented as a pilot study to elucidate biographical data and different needs of young patients regarding fertility issues, pregnancy, parenthood, and medical counseling. As our cohort comprised a small sample of patients without a control group and had a cross-sectional design with a short follow-up period, generalizability of the results may be limited. Moreover, questionnaires were often not fully completed by the patients. However, the study still reflects certain deficits in current medical counseling and the need for further research in order to offer young BC patients care tailored to their particular needs. The next step following these results will be to roll out this study into a multicenter and prospective study design (in progress). 
In summary, our study demonstrates the importance of addressing fertility issues and parenthood concerns during medical counseling. Young BC survivors reported a lack of communication related to parenthood concerns and future conception, but satisfaction with counseling on fertility preservation and genetics. No significant results were found regarding partnership and employment status. With regard to these data, new and individualized strategies need to be developed for better support of young BC patients throughout the course of their disease.

\section{Acknowledgement}

The authors thank the participating patients of the study for their collaboration.

The study was in accordance with the ethical standards of the institutional research committee and with the 1964 Helsinki declaration and its later amendments or comparable ethical standards.

\section{Disclosure Statement}

The authors declare that they have no conflict of interest.

\section{References}

1 Partridge $\mathrm{AH}$, Pagani $\mathrm{O}$, Abulkhair $\mathrm{O}$, et al: First international consensus guidelines for breast cancer in young women (BCY1). Breast 2014;23:209-220.

2 Cardoso F, Loibl S, Pagani O, et al.; European Society of Breast Cancer Specialists: The European Society of Breast Cancer Specialists recommendations for the management of young women with breast cancer. Eur J Cancer 2012;48:3355-3377.

3 Paluch-Shimon S, Pagani O, Partridge AH, et al: Second international consensus guidelines for breast cancer in young women (BCY2). Breast 2016;26:87-99.

4 Brinton LA, Sherman ME, Carreon JD, Anderson WF: Recent trends in breast cancer among younger women in the United States. J Natl Cancer Inst 2008;100:16431648

5 Leclere B, Molinie F, Tretarre B, et al.; GRELL Working Group: Trends in incidence of breast cancer among women under 40 in seven European countries: a GRELL cooperative study. Cancer Epidemiol 2013; 37:544-549.

6 Pronzato P, Mustacchi G, De Matteis A, et al: Biological characteristics and medical treatment of breast cancer in young women-a featured population: results from the NORA study. Int J Breast Cancer 2011;2011: 534256.

7 Banz-Jansen C, Heinrichs A, Hedderich M, et al: Characteristics and therapy of premenopausal patients with early-onset breast cancer in Germany. Arch Gynecol Obstet 2012;286:489-493.

8 Pfeiler G: Systemic treatment in premenopausal patients with breast cancer. Breast Care 2015;10:305-306

9 Jeruss JS, Woodruff TK: Preservation of fertility in patients with cancer. N Engl J Med 2009;360:902-911.

10 Arora NK, Gustafson DH, Hawkins RP, et al: Impact of surgery and chemotherapy on the quality of life of younger women with breast carcinoma: a prospective study. Cancer 2001;92:1288-1298.

11 Lawrenz B, Henes M, Neunhoeffer E, Kraemer B, Fehm T: Fertility conservation in breast cancer patients. Womens Health (Lond) 2011;7:203-212.

12 Davies C, Pan H, Godwin J, et al.; Adjuvant Tamoxifen: Longer Against Shorter (ATLAS) Collaborative Group: Long-term effects of continuing adjuvant tamoxifen to 10 years versus stopping at 5 years after diagnosis of oestrogen receptor-positive breast cancer: ATLAS, a randomised trial. Lancet 2013;381:805-816.

13 Llarena NC, Estevez SL, Tucker SL, Jeruss JS: Impact of fertility concerns on tamoxifen initiation and persistence. J Natl Cancer Inst 2015;107.pii:djv202.
14 Weaver KE, Rowland JH, Alfano CM, McNeel TS: Parental cancer and the family: a population-based estimate of the number of US cancer survivors residing with their minor children. Cancer 2010;116:43954401

15 Hauglann B, Benth JS, Fossa SD, Dahl AA: A cohort study of permanently reduced work ability in breast cancer patients. J Cancer Surviv 2012;6:345-356.

16 Ferlay J, Parkin DM, Steliarova-Foucher E: Estimates of cancer incidence and mortality in Europe in 2008. Eur J Cancer 2010;46:765-781.

17 Islam T, Dahlui M, Majid HA, et al.; MyBCC study group: Factors associated with return to work of breast cancer survivors: a systematic review. BMC Public Health 2014;14(suppl 3):S8

18 Carlsen K, Dalton SO, Frederiksen K, Diderichsen F, Johansen C: Are cancer survivors at an increased risk for divorce? A Danish cohort study. Eur J Cancer 2007; 43:2093-2099.

19 Dorval M, Maunsell E, Taylor-Brown J, Kilpatrick M: Marital stability after breast cancer. J Natl Cancer Inst 1999;91:54-59.

20 Ruddy KJ, Gelber SI, Tamimi RM, et al: Prospective study of fertility concerns and preservation strategies in young women with breast cancer. J Clin Oncol 2014; 32:1151-1156.

21 Senkus E, Gomez H, Dirix L, et al: Attitudes of young patients with breast cancer toward fertility loss related to adjuvant systemic therapies. EORTC study 10002 BIG 3-98. Psychooncology 2014;23:173-182.

22 Janz NK, Friese CR, Li Y, Graff JJ, Hamilton AS, Hawley ST: Emotional well-being years post-treatment for breast cancer: prospective, multi-ethnic, and population-based analysis. J Cancer Surviv 2014;8:131-142.

23 Maunsell E, Brisson C, Dubois L, Lauzier S, Fraser A: Work problems after breast cancer: an exploratory qualitative study. Psychooncology 1999;8:467-473.

24 Luoma ML, Hakamies-Blomqvist L: The meaning of quality of life in patients being treated for advanced breast cancer: a qualitative study. Psychooncology 2004;13:729-739.

25 Loh SY, Packer T, Chinna K, Quek KF: Effectiveness of a patient self-management programme for breast cancer as a chronic illness: a non-randomised controlled clinical trial. J Cancer Surviv 2013;7:331-342.

26 Turner J, Kelly B, Swanson C, Allison R, Wetzig N: Psychosocial impact of a newly diagnosed advanced breast cancer. Psychooncology 2005;14:396-407.
27 Kennedy VL, Lloyd-Williams M: How children cope when a parent has advanced cancer. Psychooncology 2009;18:886-892.

28 Turner J, Clavarino A, Yates P, Hargraves M, Connors V, Hausmann S: Development of a resource for parents with advanced cancer: what do parents want? Palliat Support Care 2007;5:135-145.

29 De Vos M, Smitz J, Woodruff TK: Fertility preservation in women with cancer. Lancet 2014;384:13021310

30 Von Wolff M, Montag M, Dittrich R, Denschlag D, Nawroth F, Lawrenz B: Fertility preservation in women - a practical guide to preservation techniques and therapeutic strategies in breast cancer, Hodgkin's lymphoma and borderline ovarian tumours by the fertility preservation network FertiPROTEKT. Arch Gynecol Obstet 2011;284:427-435.

31 Siegel K, Gorey E, Gluhoski V: Pregnancy decision making among women previously treated for breast cancer. J Psychosoc Oncol 1997;15:27-42.

32 Yee S, Abrol K, McDonald M, Tonelli M, Liu KE: Addressing oncofertility needs: views of female cancer patients in fertility preservation. J Psychosoc Oncol 2012;30:331-346.

33 Dow KH: Having children after breast cancer. Cancer Pract 1994;2:407-413.

34 Bloom JR, Stewart SL, Chang S, Banks PJ: Then and now: quality of life of young breast cancer survivors. Psychooncology 2004;13:147-160.

35 Laitala VS, Saarto T, Einio EK, Martikainen P, Silventoinen K: Early-stage breast cancer is not associated with the risk of marital dissolution in a large prospective study of women. Br J Cancer 2015;113:543-547.

36 Jalovaara M: Socioeconomic resources and the dissolution of cohabitations and marriages. Eur J Population 2013;29:167-193.

37 Syse K: Does cancer affect the divorce rate? Demogr Res 2007;16:469-492.

38 Mellette SJ: The cancer patient at work. CA Cancer I Clin 1985;35:360-373.

39 Clark JC, Landis LL: Reintegration and maintenance of employees with breast cancer in the workplace. AAOHN J 1989;37:186-193.

40 Ferrell BR, Grant MM, Funk B, Otis-Green S, Garcia $\mathrm{N}$ : Quality of life in breast cancer survivors as identified by focus groups. Psychooncology 1997;6:13-23. 